\title{
Uma experiência de ler e reescrever a escola: as ocupações escolares de 2015
}

\author{
Mirza Laranja ${ }^{1}$ \\ Beatriz Barud ${ }^{2}$ \\ Rita de Cássia Alves Oliveira ${ }^{3}$ \\ Rafael de Paula Aguiar Araújo ${ }^{4}$
}

\begin{abstract}
Resumo:
Este artigo apresenta a percepção de jovens durante o movimento estudantil de ocupações das escolas de ensino médio no estado de São Paulo, no ano de 2015. A narrativa deste estudo está construída a partir de referenciais teóricos e reflexões das autoras, ilustradas por falas de três adolescentes, personagens do filme documentário "Espero Tua (Re)Volta", da roteirista e diretora Eliza Capai. Trechos selecionados permitem compreender aspectos relevantes do cotidiano das ocupações, a partir dos quais segue a discussão em duas perspectivas: a juventude como agente político social e a desta como estudante no espaço da escola. A relação entre juventude e escola é de tensão, muito embora esta seja uma instituição muito importante para os(as) jovens, considerada o principal canal para mobilidade social. As conclusões sugerem novas questões, alertando à possibilidade de que as tentativas de aproximação entre a escola e jovens podem fracassar, pelo fato de haver uma distância entre o "ser jovem hoje" e aquilo que as instituições educativas esperam dele.
\end{abstract}

\section{Palavras-chave:}

Movimento Estudantil. Ocupações de Escolas. Ensino Médio. Juventude.

\section{An experience of reading and rewriting the school: the school occupations of 2015}

\footnotetext{
Abstract: In 2015, the student movement promoted occupations in public high schools in the State of São Paulo in reaction to the government educational reform. This article presents the perception of young people about this movement during the occupation period. This study's narrative is based

1 Doutoranda em Ciências Sociais pela Pontifícia Universidade Católica de São Paulo. E-mail: mirzalaranja@uol.com.br. ORCID iD: http://orcid.org/0000-0001-5193-0935.

2 Doutoranda em Ciências Sociais pela Pontifícia Universidade Católica de São Paulo. E-mail: beatrizbarud@gmail.com. ORCID iD: http://orcid.org/0000-0002-9093-0716.

3 Doutora em Antropologia, Docente do Programa Pós-Graduação em Ciências Sociais da Pontifícia Universidade Católica de São Paulo. E-mail: ritaalves@pucsp.br. ORCID iD: http://orcid.org/0000-0002-9080-6440.

4 Doutor em Ciências Sociais, Docente do Programa de Pós-Graduação em Ciências Sociais da Pontifícia Universidade Católica de São Paulo. E-mail: rafael.araujo1977@gmail.com. ORCID iD: http://orcid.org/0000-0002-7632-6053.
} 
on the authors' theoretical references and reflections, illustrated by three teenagers' speeches, characters from the documentary film "Espero Tua (Re) Volta" by the screenwriter and director Eliza Capai. Relevant aspects of daily life during the occupations are revealed by the selected extracts. The discussion follows from two perspectives: youth as social political agent and youth as students in the school space. The relationship between youth and school is tense, even though this is a significant institution for young people, for opening doors to social mobility. The conclusions suggest new issues for researchers, alerting to the possibility that attempts to bring schools and young people closer together can fail due to the distance between "being young today"; and what educational institutions expect of them.

Keywords: Student Movement. School Occupations. High school. Youth.

\section{Una experiencia de leer y volver a escribir la escuela: las ocupaciones escolares de 2015}

Resumen: Este artículo presenta la percepción de los jóvenes durante el movimiento estudiantil de ocupaciones en las escuelas secundarias del estado de São Paulo, en el año 2015. La narrativa de este estudio se construye a partir de referencias teóricas y reflexiones de los autores, ilustradas por declaraciones de tres adolescentes, personajes del documental "Espero Tua (Re) Volta", por la guionista y directora Eliza Capai. Extractos seleccionados permiten comprender aspectos relevantes de las ocupaciones cotidianas, de los cuales se desprende la discusión desde dos perspectivas: la juventud como agente político social y esta misma juventud cuando en el espacio escolar se convierten en estudiantes. La relación entre la juventud y la escuela es tensa, aunque se trata de una institución muy importante para los jóvenes, considerada el principal medio para la movilidad social. Las conclusiones plantean nuevos temas y alertan sobre la posibilidad de que los intentos de acercar a las escuelas y los jóvenes han fracasado debido a la distancia entre lo que es "ser joven hoy" y lo que las instituciones educativas esperan de ellos.

Palabras Clave: Movimiento estudiantil. Ocupaciones escolares. Escuela secundaria. Juventud.

\section{Introdução}

"Viver de um espaço e um lugar em que eu nunca estive antes." (51:28) assim se expressa uma das personagens do filme Espero Tua (Re)Volta, que retrata a perspectiva de três estudantes que participaram das ocupações de escolas, no ano de 2015 em São Paulo. Durante o movimento, meninos e meninas redescobriram a si, aos outros e ao espaço da escola (CAMPOS; MEDEIROS; RIBEIRO, 2016). Um tempo e lugar onde, na fala da protagonista, foi possível: "escolher o que eu quisesse ser" (52:00).

Naquele ano, mais de 200 unidades escolares de ensino médio no estado de São Paulo foram ocupadas durante 60 dias. Eram jovens em luta por suas escolas, uma causa que foi capaz de mobilizá-los intensamente, pois como aponta a pesquisa Juventude e Conexões realizada pela Fundação Telefônica Vivo (OLIVEIRA, 2019), pouco se interessam por política e para quem ação social pode ser encarada de forma muito ampla e fluida.

O movimento causou surpresa a todos: população em geral, governo, gestores escolares, familiares, eles próprios e academia. Isto porque, como nas palavras de outro narrador e personagem do filme: "Os caras não sabem mesmo o que fazer com a gente. Pobre causando é bandido. São umas crianças!” (41:30).

Assim como as tantas outras manifestações estudantis que se multiplicaram no país, as ocupações escolares tornaram-se tema de inúmeros registros, estudos, pesquisas e artigos científicos (GOHN, 2018; CAMPOS; MEDEIROS; RIBEIRO, 2016). Estas análises são em geral produzidas com o objetivo de entender este processo de mobilização, de luta política, conduzida, sobretudo, por jovens em idade escolar e que demonstrou uma força capaz de suscitar inúmeras questões. 


\section{Objetivos}

Este artigo tem por objetivo compreender, por meio do cinema, questões do cotidiano de jovens em suas escolas durante o movimento estudantil de ocupações no ano de 2015, em São Paulo, que se mostrou uma experiência de ler e reescrever a escola. O texto está organizado em cinco seções: (1) introdução; (2) objetivos; (3) método; (4) resultado apresentado por meio de trechos do filme que foram selecionados pelos autores, após várias releituras e um trabalho de divisão, que visou compreender mais diretamente aspectos relevantes do cotidiano das ocupações; (5) discussão em duas perspectivas: a primeira dedicada a apresentar uma discussão teórica sobre juventude como agente político social; e em seguida abordar a juventude no espaço da escola; (6) como conclusões, o artigo traz algumas reflexões e novas proposições.

A narrativa deste estudo está construída a partir de referenciais teóricos e reflexões das autoras, ilustradas por falas de personagens do documentário Espero Tua (Re)volta ${ }^{1}$. Ao lado das falas transcritas, está apontado o tempo decorrido no filme onde se localizam.

\section{Método}

Este artigo adota uma perspectiva particular. Seu interesse está centrado na experiência destes jovens durante o período em que fizeram de suas escolas um espaço para viver, para se conhecer e para constituir uma comunidade. Um novo cotidiano, num espaço já velho conhecido. Diante do foco escolhido, cabe uma metodologia científica qualitativa, na qual os protagonistas do evento são também objetos de estudo. E como fazê-lo?

Tomou-se como ponto de partida o registro desta história na obra da roteirista e diretora Eliza Capai, o filme Espero Tua (Re)volta ${ }^{2}$. O documentário retrata o movimento estudantil de 2015 a partir de imagens de arquivo e apresenta e preserva a perspectiva dos adolescentes que fizeram parte das ocupações das escolas secundaristas no estado de São Paulo. Com o intuito de retratar as ocupações, o documentário é didático e se atém em demonstrar a lógica da mobilização, seu diferencial está em sua narrativa verbal e visual, capaz de criar uma intimidade com aquelas pessoas que lá se expunham. Espero Tua (Re)volta é uma produção coletiva da qual participam ativamente os atores-sujeitos, que trazem suas memórias, testemunhos e interpretações. Por meio dela, se faz evidente o profundo significado da experiência para a vida de cada estudante.

Assim, para compreender as falas dos estudantes e apresentá-las neste trabalho, utilizou-se de noções acerca da técnica de análise do discurso que permite o estudo da relação entre língua, discurso e ideologia. Esse campo de estudo se desenvolve a partir de cada pesquisa, não está pronto e acabado, ou seja, teoria e método se desenvolvem mutuamente. A escolha pela análise do discurso se deu, pois é essa técnica que permite fornecer sentido a fenômenos sociais a partir dos significados que os sujeitos daquele fenômeno atribuem. Sendo assim, na análise do discurso o sujeito é considerado em sua essência, isto é, enquanto sujeito social, histórico e cultural (SILVA; ARAÚJO, 2017).

A opção metodológica de analisar o documentário acima mencionado encontrou inspiração em pesquisadores que subverteram as fronteiras entre arte e ciência, como Jean Rouch, que, nas

\footnotetext{
1 Agradecimentos à Taturana Mobilização Social, distribuidora do filme nos cinemas, que também disponibiliza o longa em sua plataforma (www.taturanamobi.com.br), de forma gratuita, para quem quiser organizar uma sessão pública do filme.

2 Espero Tua (Re)volta recebeu entre outros os prêmios de melhor documentário nos festivais FICIP (Festival Internacional de Cine Político) na Argentina; na Mostra de Cinema Latinoamerica de Catalunya, na Espanha; e no Sneakers Film Festival for Children and Youth, na Polônia. Recebeu também o Grand Prix no Internacional Festival of Red Cross and Health Films, na Bulgária, e o Prêmio Olhar, na Mostra Festival Olhar de Cinema, em Curitiba. Prêmio da Associação Brasileira de Críticos de Cinema - Abraccine, na 23ạ edição do Cine-PE. Prêmio Peace Film Mostra Generation 14plus do Festival de Berlim e Prêmio da Anistia Internacional.
} 
palavras de Rose Satiko Gitirana Hikiji (2013, p. 113), "híbrido de cineasta e antropólogo, é figura 'boa para pensar' ambos os fazeres". Hikiji também constrói sua pesquisa e arte, usando o cinema, em produções que transitam entre documentário e ficção, real e imaginário, pensadas e narradas por personagens que vivem o contexto.

\section{Resultados}

Um cotidiano de novas descobertas, num espaço já velho conhecido

Muito se aborda o tema das ocupações, concebendo-as como tática de luta e instrumento de ação política, mas pouco se debruça sobre a singularidade desta estratégia, dada a complexidade, esforço demandado e impacto na vida das pessoas envolvidas. É uma experiência emocional intensa, cansativa e uma ruptura com o vivido até então. Mais ainda quando estas ocupações são protagonizadas por jovens.

Como bem ilustra Le Breton, sociólogo e antropólogo, ao estudar os sentidos menciona que a percepção é também interpretação. O autor apresenta uma reflexão sobre uma mesma floresta que é percorrida por sujeitos diferentes:

[...] Percorrendo a mesma floresta, indivíduos diferentes não são sensíveis aos mesmos dados [...] Mil florestas na mesma, mil verdades de um mesmo mistério que se esquiva e que jamais se dá senão em fragmentos. Não existe a verdade da floresta, mas uma infinidade de percepções. (LE BRETON, 2016, p. 12).

Partindo das premissas acima mencionadas, de que diferentes sujeitos constroem diferentes interpretações, pretende-se nesta seção, percorrer o ambiente escolar em tempo de ocupação estudantil partindo da perspectiva de meninos e meninas que lá estiveram, na certeza de que toda visão é em si uma interpretação de quem a percebe.

Com este objetivo, foram selecionadas passagens do documentário que permitiram revelar as percepções e interpretações das personagens protagonistas sobre o espaço escolar.

Tendo como referência a cartilha Como Ocupar Uma Escola produzida pelo coletivo O Mal Educado, no final de 2013, os estudantes logo perceberam que passariam a conviver ali por algum tempo. Diante do modelo organizativo a que se propunham, seria necessário discutir a cada ação ou decisão, um exercício constante e intenso de política e democracia, desconstruindo um modelo vivido até então naquele mesmo local (CAMPOS; MEDEIROS; RIBEIRO, 2016). Para os jovens, o cotidiano escolar, em sua rotina tradicional, não parecia ser um espaço de aprendizagem, mas um lugar onde se percebem: "treinados prá virar mão de obra barata, baixar a cabeça, obedecer, não discutir, aceitar. Chega." (37:32) [sic].

Certamente as experiências de ocupação foram muito diversas em cada unidade escolar, mas foi possível identificar um traço importante comum a todas, a autogestão horizontal, na qual escutar o outro é um exercício constante: "Isso de fazer assembleia para decidir como seria a ocupação, foi em todas as escolas. Aliás, a assembleia geral decidia se teria ocupação.” (34:34) [sic].

Constituíram-se cerca de 200 comunidades artificiais, criadas politicamente pelas ocupações (NOBRE, 2019, p. 10), e que proporcionaram aprendizado político, por meio da vivência coletiva, criação de comissões, organização de trabalho, etc.: "A medida que for tendo necessidade de limpeza, arrumar cadeira... a gente vem aqui, fala da comissão e quem quiser se candidata." (37:50) [sic].

Surpreendidos por suas próprias competências, por meio desta experiência os estudantes buscaram provar: "que mesmo a gente sendo adolescente, a gente pode cuidar de uma escola." (47:27) [sic]. E o fizeram à luz do que desejavam para este espaço, reconhecido e relevante para os 
estudantes. Esta nova escola foi recheada de rodas de conversas que abordavam assuntos evitados no currículo escolar, e modos de relação social com os quais queriam romper, tais como machismo: "A ocupação não vai ser um espaço machista que nem a escola é - só mulheres na limpeza e na merenda" e racismo "respeitar cada traço do rosto, a história dos ancestrais." (49:00) [sic].

No cotidiano das ocupações manifestavam-se também os valores que os estudantes traziam consigo a partir da convivência familiar. Cuidavam do lugar que seria seu lar por até dois meses. Aprenderam com a arte do fazer, a cozinhar, limpar, organizar, consertar... Criaram em cada escola um território privado que muito revela sobre seus habitantes. Objetos, paredes, forma de uso dos espaços e a distribuição das funções diárias. Em cada escola, se desenvolveram cotidianos e modos de fazer, que proporcionaram certa segurança familiar, reconhecimento e acabaram aproximando as pessoas que ali se encontravam.

Não por acaso, um dos primeiros e principais temas discutidos era a alimentação. Providenciar insumos, quais pratos preparar, quantas pessoas a alimentar, horários de refeição, enfim, mais do que pela necessidade de sobrevivência, as refeições comunitárias criam vínculos importantes. Assim, a experiência foi também uma oportunidade para dar valor ao saber fazer, o que não é tradicionalmente reconhecido na mesma medida de outros saberes.

A música, capaz de marcar o tempo, despertar afetos, provocar a reflexão, e especialmente de levar uma mensagem esteve muito presente ao longo do movimento, tanto no filme, quanto nas ocupações. Esta forma de manifestação cultural intimamente relacionada ao modo de ser juvenil e que tão raramente encontra espaço na rotina anestesiada da escola.

Meninos e meninas puderam desconstruir um modelo de escola e anteciparam a escola desejada, na qual aprender tem origem nas relações de afeto entre si, conhecendo: "pessoas com quem estava estudando há muito tempo. Isso que mais marcou a ocupação." (47:00) [sic] e na relação de afeto com o espaço, experienciando: "um espaço e um lugar em que eu nunca estive antes." (51:28) [sic].

\section{Discussão}

\section{Juventude como agente político social}

Desde a segunda metade do século XX, a juventude vem ganhando visibilidade devido à confluência de três fatores: a reorganização econômica e produtiva da sociedade, a oferta de consumo cultural e o discurso jurídico marcado pela universalização dos direitos humanos. Traz em si um "conceito": um modo de entender o mundo e um mundo para cada "estilo", fruto de uma tensão identidade-diferenciação; efeito simbólico, não por isso menos real, ao identificar-se com iguais e diferenciar-se dos outros, em especial dos adultos (REGUILLO, 2012).

Apenas a noção de idade não é suficiente para definir o que é ser jovem, por exemplo, se olharmos para o Estatuto de Juventude (Lei 12.852/13), jovem é definido como aquele que tem entre 15 e 29 anos, ademais, a noção de jovem também sofre influência do contexto e lugar social ocupado pelo jovem, por essa razão é que devemos pensar e falar em juventudes, pois existem múltiplas abordagens, sendo a idade uma delas, as condições socioeconômicas outro e a condição e situação juvenil uma terceira abordagem (GOHN, 2018). Este trabalho manteve seu olhar para os jovens que possuem de 15 a 18 anos e que são secundaristas de escolas públicas de São Paulo. É importante ressaltar que a mobilização destes jovens contribuiu para superar a ideia de que o jovem ou estava sob uma perspectiva romântica, representando a esperança de um futuro melhor, ou era o símbolo da violência das cidades, dos problemas sociais, da rebeldia e da delinquência. A ocupação das escolas demonstrou que os jovens são sujeitos engajados em seu contexto social, que não estão alienados do que acontece nos ambientes que frequentam e, mais além, demonstrou que eles podem ser - e são atores sociais. 
Nas ciências sociais as pesquisas vinham se dedicando a jovens e juventudes, da perspectiva de sua diversidade e pluralidade, seja com interesse por questões relativas à faixa etária, ou a aspectos socioeconômicos. No século XXI os jovens alegaram que a modernidade não possuía um projeto capaz de cumprir sua promessa de um futuro inclusivo, justo e possível, de modo que em sociedades ocidentais em que o mundo do trabalho é o ponto de chegada da realização pessoal, muita expectativa é depositada nos jovens e em suas escolhas (TRANCOSO; OLIVEIRA, 2016). Tal fato fez aumentar o interesse de muitos pesquisadores nas práticas, comportamentos e participações destes jovens na sociedade, lançando luz em seus comportamentos.

Maria da Glória Gohn ensina que o Brasil concentrava, em 2010, 50\% dos jovens da América Latina, correspondendo a 34 milhões de jovens. A autora segue e diz que na atualidade esses números cresceram e apontam que o número de desempregados é maior entre os jovens. Sendo assim, crises econômicas e políticas que resultam em recessão, corrupção e violência "formam um caldo que destrói a confiança e a esperança no futuro" (GOHN, 2018, p. 117).

Um cenário assim propicia o surgimento de manifestações e protestos em espaços públicos, com participação majoritária de jovens ou mesmo movimentos mobilizados por eles. Vale mencionar: as jornadas de junho de 2013 e as ocupações das escolas em 2015 e 2016 (GOHN, 2018). Tais movimentos permitiram o fortalecimento de uma pauta diversa com temas relacionados a direitos humanos, e em destaque educação, por uma educação de qualidade, que cumpra com a promessa de empregabilidade e mobilidade social. No documentário um relato transmite o descontentamento com o cenário atual, sobretudo o desemprego: Mas como? "Trabalhar do que se a gente não tem nem formação? Ter formação como, se a gente estuda numa sala superlotada, que é normal professor faltar?” (49:00) [sic].

A juventude busca suas formas para reivindicar o que entende por direito. Mas, em geral, escola e gestão pública continuam a pensar a juventude como uma fase de transição, uma etapa de preparação para a vida adulta. Assim, a educação se distancia de seus valores, fortemente ancorados na realidade presente, de seus anseios e não reconhece os(as) jovens como pessoas competentes para se colocar diante do mundo e das instituições, agentes sociais ativos na sociedade:

A escola não ensina a gente a se organizar politicamente. A escola não ensina sobre movimentos sociais. A escola não debate quais são as melhores formas de se questionar, de transformar a sociedade. E eu acredito que isso não é por acaso. Eles simplesmente nos ensinam que se organizar não é o caminho, que é crime, inclusive. (26:00) [sic].

E ainda: "saber que o governador estava comunicando a gente que a gente ia mudar de escola, sem saber se a gente queria ou não trocar de escola, foi uma coisa antidemocrática" (32:51) [sic].

E "sem liderança", certos de que nada nem ninguém os representava, estudantes paralisaram e ocuparam 200 escolas durante 60 dias, contra o plano de reorganização das escolas estaduais paulistas. Aprenderam com seus pares e empoderam-se por meio da arte: "Chegou em nosso poder uma história de uns estudantes do Chile. A Revolta Dos Pinguins ${ }^{3}$, um documentário." (29:00) [sic].

Como aponta Reguillo (2012), o cinema e a literatura têm produzido aproximações, análises e críticas interessantes sobre espaços tradicionais de socialização, sem perder de vista o sujeito juvenil. Inspiraram-se também em outros movimentos sociais, como o Movimento Sem Teto que usa ocupações como ferramenta de luta, que na fala de um de seus líderes declarou: "As escolas que fecharem, nós vamos ocupar" (28:45). Para os estudantes, se era para alguém ocupar escolas, que cada

3 Filme do diretor Carlos Pronzato, ganhador do Prêmio Especial do Juri na XXXVI Jornada Internacional de Cinema da Bahia (2009) e do Prêmio Internacional Roberto Rossellini, no Festival de Maiori, na Itália (2009). Este documentário registra a luta dos "pinguins", como são conhecidos os estudantes secundaristas chilenos, por meio de protestos de rua e principalmente ocupações de colégios (maio de 2006), exigindo não só melhorias na educação, mas também mudanças estruturais no país. 
estudante ocupe a sua, de modo que aos poucos foram surgindo notícias das escolas ocupadas em outros lugares além de Diadema e Pinheiros (CAMPOS; MEDEIROS; RIBEIRO, 2016): "E mesmo sem saber ao certo como surgiu a ideia, o movimento 'frutificou'." (32:00) [sic].

O movimento ganhou as grandes redes e mídias sociais. São as tecnologias de comunicação impactando diretamente na forma de atuar socialmente e fazer política, ao gerar imbricadas articulações entre os universos on-line e off-line. Mesmo porque a juventude contemporânea também considera a divulgação e compartilhamento de informações em suas redes sociais digitais, ou mobilizações e abaixo-assinados on-line, como formas válidas de participação social (OLIVEIRA, 2019).

De variadas formas, jovens estudantes partem para construir uma vida política distante dos modelos de participação institucional, por entenderem que cidadania é construída a partir da experiência (GOHN, 2018), e demonstram estar dispostos a sacrifícios que só os que participaram das ocupações poderão dimensionar: "Lá dentro a gente tá super cansado, não dorme direito sentimento lá dentro é medo.” (43:00).

\section{Juventude como alunos e alunas}

Vivemos uma sociedade em significativa transformação, marcadamente pela midiatização, mundialização da cultura e por interações sociais que superam barreiras de tempo e espaço. Neste novo contexto, as instituições tradicionais já não têm mais a exclusividade pela socialização da juventude.

A escola, assim como a família, disputa com outras instâncias de vida que também aportam referências de valores e modos de vida. O "desmoronamento dos muros", como descreve Dayrell (2007), implica em processos permeáveis, intercambiáveis e por vezes contraditórios. Como consequência, a relação entre juventude e escola vive uma tensão, reforçada pela polarização das partes. Educadores, atribuindo às novas mídias e estilos de vida a culpa por retirar dos jovens o interesse pela escola. Juventude, reduzindo a escola a uma "obrigação necessária" - parafraseando o autor, apesar de considerá-la ultrapassada. Por outro lado, a juventude continua a ver a escola como uma instituição muito importante, o principal canal para mobilidade social, como a história de vida de Marcela: "Minha avó era analfabeta e minha mãe não terminou nem o fundamental 2. Eu sou a primeira a terminar o ensino médio." (14:45) [sic].

Jovens nesta etapa escolar, entre seus 15 e 18 anos, através de seus corpos experienciam a si, aos outros e ao mundo. A adolescência marca um período de alterações morfológicas, fisiológicas e bioquímicas, de quem está a crescer. Mas além do processo biológico, múltiplas outras transformações acontecem nesta fase de (re)construção de si e do mundo, em meio a intensas experiências sensoriais na música, dança, esporte, sexo, etc.

Toda discussão acerca da juventude na escola, além da sua dimensão histórico-geracional, deve considerar mais especificamente a condição desta sua parcela que frequenta as escolas públicas brasileiras, em sua maioria residentes de regiões periféricas das grandes e desiguais metrópoles, e particulares em seus modos de vida quanto a tempos, espaços, recortes de classe, gênero, etnia, etc. Sabidamente as experiências sociais vivenciadas em múltiplas dimensões influenciam diretamente o cotidiano escolar, mas a escola não consegue perceber a diversidade da condição juvenil. Está presa no modelo de "aluno" que a sociedade projeta e reforça.

No cotidiano escolar, o jovem vivencia o "vir a ser", à luz de um modelo de aluno ideal criado pela escola. Mas há uma distância entre o "ser jovem hoje" e aquilo que as instituições educativas esperam dele. Para Dayrell (2007), a ideia de "aluno" é tida como algo natural, "marcada por uma relação assimétrica" entre aquele que ensina e aquele que aprende - no caso do ensino básico regular, uma relação entre adultos e crianças ou jovens. Entretanto, na contramão do movimento homogeneizante da escola, "os jovens alunos, nas formas em que vivem a experiência escolar, estão dizendo que não querem tanto ser tratados como iguais, mas, sim, reconhecidos nas suas especificidades, $o$ que implica serem reconhecidos como jovens, na sua diversidade..." (DAYRELL, 2007, p. 1125). 
No modelo criado no Estado moderno, a escola é responsável pela formação do cidadão, ao mesmo tempo em que deve discipliná-lo e inseri-lo na sociedade. Mas a escola não pode ser um espaço ou tempo no qual os jovens e as jovens sejam apenas preparados para um futuro. Lá também é o lugar e o tempo presente onde se vivencia a juventude.

Enquanto que na rotina escolar os jovens convivem com normas disciplinadoras, controladoras e homogeneizantes, que vão do uso de uniforme a restrições das mais diversas, durante as ocupações, os jovens se expressaram, escolhendo roupas e adereços e assim puderam "experimentar o mundo, percebendo-o a seu próprio estilo, numa estreita relação entre cotidianos escolares, suas vivências nos espaços públicos, suas identidades e pertencimentos e a dimensão estética dos corpos" (OLIVEIRA, 2019, p. 109). Nesse sentido, relembrou um jovem da ocupação: "Revolução é assim mesmo. Ocupar a rua é político e trazer esta revolução para os nossos corpos também é um ato revolucionário." (11:25) [sic].

A organização dos jovens para reivindicar o espaço escolar e impedir o fechamento das escolas demonstra que os jovens estão ligados ao que acontece nas diversas esferas públicas. A ocupação das escolas promoveu mudanças na estrutura escolar e em seu currículo com o objetivo de diminuir a distância entre o pensamento dos jovens e a estrutura da escola. Contudo, não é possível afirmar que esta batalha está vencida, é preciso se atentar para o fato de que essas decisões não seriam "adultocêntricas" ou seja, mais uma forma de diminuir a mobilização dos jovens, realimentando um processo de escolarização das manifestações juvenis.

\section{Conclusões}

As ocupações de escolas paulistas em 2015 tiveram como causa deflagradora a reorganização das unidades escolares da rede estadual de ensino. A luta destes e destas jovens levou o governo à época a recuar em sua decisão. Independentemente deste fator mais objetivo, o movimento certamente gerou aprendizados e impactos profundos principalmente na vida das pessoas diretamente envolvidas. Como nos ensinou o educador Paulo Freire (1987), há que se aprender a ler a realidade, para poder reescrevê-la. E isto certamente estas e estes jovens alcançaram. Aprenderam entre si, mediados pela experiência.

Se aprendizagem é uma experiência de transformação, foi possível reunir neste breve artigo uma variedade delas. A ocupação em si, os registros feitos no calor da hora, a releitura pelos atores-narradores do documentário, a criação cinematográfica tão cheia de simbolismos, a experiência de espectador, o olhar observador de quem escreve este artigo, e, assim espero, sua leitura. Todos em alguma medida recriamos uma escola desejada.

O método utilizado neste artigo não pretende levar a generalizações e talvez não permita identificar eventuais inconsistências entre a retórica e a realidade. Mas nos permite conhecer a realidade percebida por estas pessoas. Restam muitas outras indagações. Onde estão hoje esses adolescentes? Como é o cotidiano nestas escolas, após as ocupações? Espera-se que este trabalho contribua para que os pesquisadores dessa temática continuem indagando sobre o poder da ação social desses jovens ou se a participação social juvenil ainda permanece fora da agenda política.

Concluímos este artigo com diferentes perguntas no horizonte e, talvez a principal delas já tenha sido colocada por uma jovem e indignada narradora: "Por que eu tenho que lutar pela minha escola sendo que isso é um direito meu?" (13:45). 


\section{Referências}

BRASIL. Lei no 12.852 . Institui o Estatuto da Juventude e dispõe sobre os direitos dos jovens, os princípios e as diretrizes das políticas públicas de juventude e o Sistema Nacional de Juventude - SINAJUVE. Brasília, DF: Presidência da República, 2013. Disponível em: http://www.planalto.gov.br/ccivil_03/_ato2011-2014/2013/lei/l12852.htm. Acesso em: 31 jan. 2021.

CAMPOS, Antonia M.; MEDEIROS, Jonas; RIBEIRO, Márcio. Escolas de Luta. São Paulo: Veneta, 2016.

DAYRELL, Juarez. A escola "faz" as juventudes? Reflexões em torno da socialização juvenil. Revista Educação e Sociedade, Campinas, v. 28, n. 100, p. 1105-1128, out. 2007. Especial. Disponível em: https://www.scielo.br/pdf/es/v28n100/ a2228100. Acesso em: 30 jan. 2021.

ESPERO tua (re)volta. Direção: Eliza Capai. Produção: Mariana Genescá. [S. l.]: Taturana Mobi, 2019. (93 min).

FREIRE, Paulo. Pedagogia do Oprimido. 17. ed. Rio de Janeiro: Paz e Terra, 1987.

GOHN, Maria da Glória. Jovens na Política na Atualidade: uma nova cultura de participação. Caderno CRH, Salvador, v. 31, n. 82, p. 117-133, jan./abr. 2018. Disponível em: https://www.scielo.br/scielo.php?pid=S0103=49792018000100117-\&scriptsci_abstract\&tlng=pt. Acesso em: 30 jan. 2021.

HIKIJI, Rose Satiko Gitirana. "Rouch compartilhado: premonições e provocações para uma antropologia contemporânea”. Iluminuras, Porto Alegre, v. 14, n. 32, p. 113-122, jan./jun. 2013. Disponível em: https://seer.ufrgs.br/iluminuras/ article/view/37743. Acesso em: 30 jan. 2021.

LE BRETON, David. Antropologia dos sentidos. Petrópolis: Vozes, 2016.

NOBRE, Marcos. Apresentação. In: MEDEIROS, Jonas; JANUÁRIO, Adriano; MELO, Rúrion (org.) Ocupar e resistir: Movimentos de ocupação de escolas pelo Brasil (2015-2016). São Paulo: Editora 34, 2019. p. 7-17.

OLIVEIRA, Rita. Participação social: Formas de atuação e usos das tecnologias digitais pelas juventudes. In: FUNDAÇÃO TELEFÔNICA VIVO; REDE CONHECIMENTO SOCIAL; IBOPE INTELIGÊNCIA. Juventudes e Conexões. 3. ed. São Paulo: Fundação Telefônica Vivo, 2019. p. 107-120. Disponível em: http://fundacaotelefonicavivo.org.br/ wp-content/uploads/pdfs/juventudes-e-conexoes_participacao.pdf. Acesso em: 30 jan. 2021.

REGUILLO, Rossana. Culturas juveniles: formas politicas del desencanto. Buenos Aires: Siglo Veinteuno, 2012.

SILVA, Jonathan Chasko da; ARAÚJO, Alcemar Dionet de. A metodologia de pesquisa em análise do discurso. Grau Zero: Revista de Crítica Cultural, Salvador, v. 1, n. 1, p. 17-31, jan./jun. 2017. Disponível em: file://C:/Users/beele/ AppData/Local/Temp/3516-Texto\%20do\%20artigo-9310-1-10-20170412.pdf. Acesso em: 31 jan. 2021.

TRANCOSO, Alcimar Enéas Rocha; OLIVEIRA, Adélia Augusta Souto. Aspectos do conceito de juventude nas Ciências Humanas e Sociais: análises de teses, dissertações e artigos produzidos de 2007 a 2011. Pesquisas e Práticas Psicossociais, São João del Rei, v. 11, n. 2, p. 278-294, jul./dez. 2016. Disponível em: http://pepsic.bvsalud.org/scielo. php?script=sci_arttext\&pid=S1809-89082016000200002\&lng=pt\&nrm=iso. Acesso em: 30 jan. 2021.

Data de submissão: 31/01/2021

Data de aceite: 09/02/2021 
